\title{
CT-guided trans-sternal iodine-125 seeds implantation for masses in the anterior or middle mediastinum
}

\author{
Meng Wang, MD*, Feng Shi, MD²*, Zhigang Zhou, MD!, Yao Cui, MS³, Kepu Du, MD!, Shuai Li, MD!, Tingting Liu, MS³ \\ Yanlin Chen, MS³, Yadan Li, MS', Fei Gao, MSl \\ "Meng Wang and Feng Shi contributed equally to this work. \\ 'Department of Radiology, The First Affiliated Hospital of Zhengzhou University, Zhengzhou, Henan, China, ${ }^{2}$ Department of Interventional \\ Treatment, Guangdong Provincial People's Hospital, Guangzhou, Guangdong, China, ${ }^{3}$ Department of Nuclear Medicine, The First Affiliated \\ Hospital of Zhengzhou University, Zhengzhou, Henan, China
}

\begin{abstract}
Purpose: The aim of this study was to explore the feasibility and clinical value of computed tomography (CT)-guided trans-sternal puncture to implant ${ }^{125}$ I seeds to treat masses in the anterior or middle mediastinum.

Material and methods: From September 2017 to December 2019, twenty patients with masses in the anterior or middle mediastinum were enrolled and treated with CT-guided trans-sternal ${ }^{125}$ I seeds implantation. Dosimetry parameters were compared between post-operative and pre-operative plans. Satisfaction rate of ${ }^{125}$ I seed distribution, complications, and local efficacy were evaluated.

Results: A total of 22 lesions were treated with ${ }^{125}$ I implantation in twenty patients, all procedures being successfully completed. The dosimetry parameters of the 20 patients immediately after surgery were as follows: mean $\mathrm{D}_{90}=134.30$ $\pm 14.53 \mathrm{~Gy}$; mean $\mathrm{V}_{90}, \mathrm{~V}_{100}, \mathrm{~V}_{150}$, and $\mathrm{V}_{200}$ were $96.10 \pm 1.55 \%, 92.69 \pm 1.93 \%, 66.86 \pm 7.53 \%$, and $42.95 \pm 9.11 \%$, respectively; mean conformity index (CI), external index (EI), and homogeneity index (HI) were $0.65 \pm 0.06,40.79 \pm 13.72 \%$, and 27.90 $\pm 7.53 \%$, respectively. The satisfaction rate of ${ }^{125} \mathrm{I}$ seed distribution was $90 \%$. The mean follow-up duration was $12 \pm 4.75$ months (range, 4-24 months). The local control rates of 2 months, 6 months, and 1 year after surgery were $65.0 \%, 64.7 \%$, and $53.8 \%$, respectively. One patient had a small degree of pneumothorax, and one had hemoptysis after surgery.

Conclusions: CT-guided trans-sternal puncture plant ${ }^{125} \mathrm{I}$ seeds for the treatment of masses in the anterior or middle mediastinum might serve as an alternative approach for treating specific mediastinal metastatic tumors.

J Contemp Brachytherapy 2022; 14, 1: 35-42 DOl: https://doi.org/10.5114/jcb.2022.113548
\end{abstract}

Key words: CT-guided, mediastinal metastasis, ${ }^{125} \mathrm{I}$ seed, real-time planning, transdermal.

\section{Purpose}

Mediastinum is a common site that harbors specific malignant tumors. Most patients with mediastinal metastases lose the chance of surgery, with chemotherapy and radiotherapy being the classic treatments. Brachytherapy is a radiotherapy technique, in which radioactive sources are precisely placed into or next to tumors, aiming at safe delivery of high doses of radiation to eliminate and shrink tumors without affecting surrounding tissues, since radiation doses rapidly decline with increasing distance from the source $[1,2]$. In contrast, intensity-modulated radiation therapy (IMRT) is an external beam form of radiotherapy that uses three-dimensional radiotherapy technology, which aims to improve local control rate of tumor development and reduce damage to adjacent normal tissues [3]. In the literature, both approaches have been compared mainly for prostate cancer treatments and to date, brachytherapy has been reported to be su- perior to IMRT [4-7]. The efficacy and safety of computed tomography (CT)-guided ${ }^{125} \mathrm{I}$ implantation for the treatment of mediastinal metastases and primary mediastinal malignant tumors has also been proven [8-10]. However, the anatomical structures in the mediastinum are complex, and lesions are often adjacent to the superior vena cava, aorta, and other great blood vessels. Furthermore, there are many structures, such as the esophagus, sternum, and thoracic vertebra in the puncture path, which potentially surround target lesions. In addition to these, the percutaneous puncture needs to pass through much of the lung tissue because the distance from mediastinal lesions to the chest wall is quite long. Therefore, a great risk of puncture exists, and it is also difficult to meet the requirements of pro-plan. In some cases with no other structures between lesions and the sternum, the use of a trans-sternal approach is safe for CT-guided biopsy of the anterior or middle mediastinal nodes $[11,12]$. How- 
ever, in contrast to CT-guided percutaneous needle approaches for intra-thoracic lesions, there are few reports about CT-guided trans-sternal ${ }^{125} \mathrm{I}$ seed implantations. Encouraged by these reports, we performed CT-guided trans-sternal ${ }^{125}$ I seeds implantation in a cohort of patients with anterior and middle mediastinal metastasis. The aim of the study was to retrospectively evaluate the feasibility and clinical value of this alternative treatment technique.

\section{Material and methods}

\section{Ethics}

This study was approved by the ethics committee of The First Affiliated Hospital of Zhengzhou University. All included patients provided informed written consent before taking part in the study.
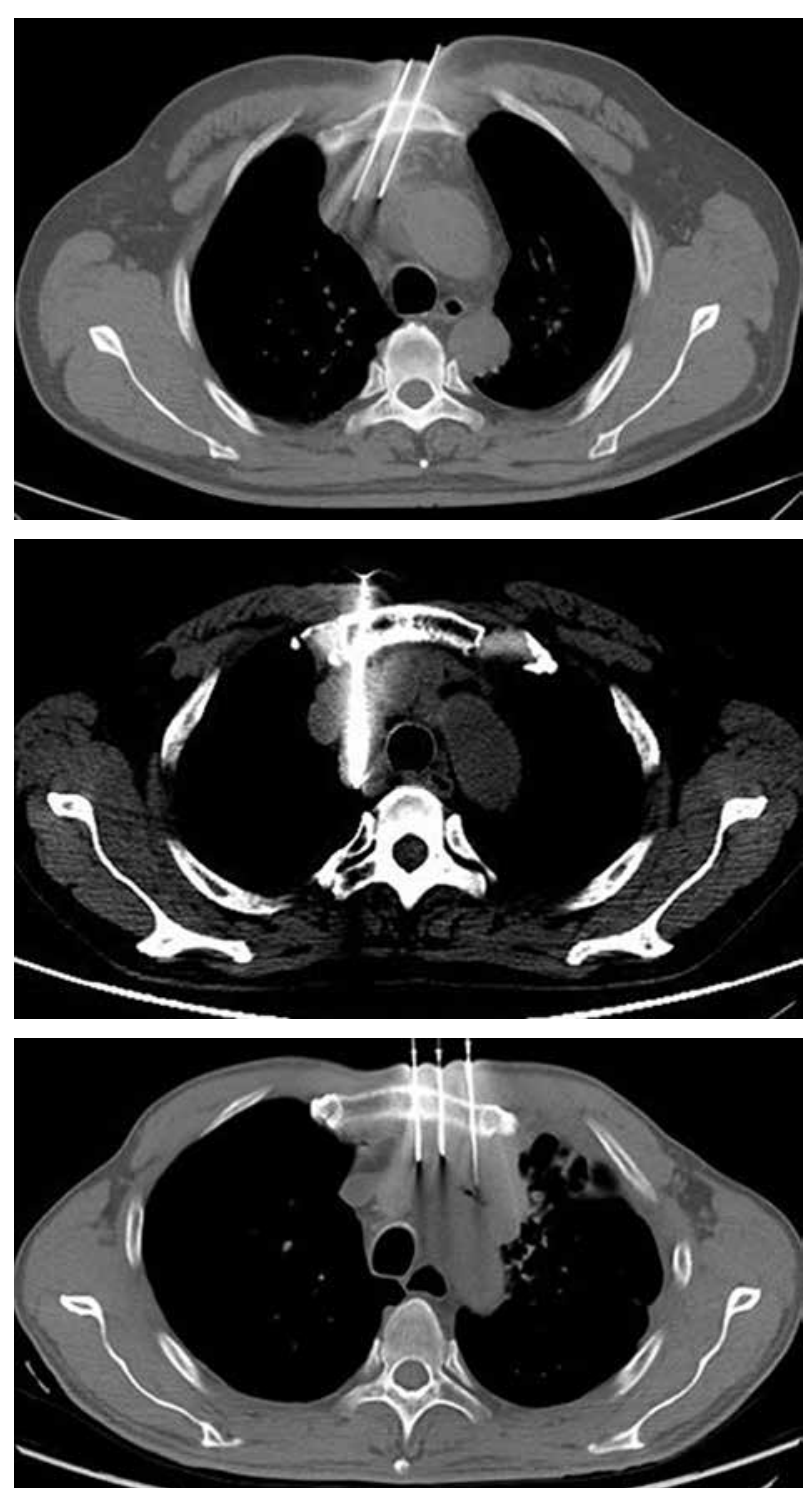

Fig. 1. Patients with anterior or middle mediastinal metastasis underwent CT-guided via trans-sternal ${ }^{125} \mathrm{I}$ seed implantation

\section{Patients}

From September, 2017 to December, 2019, twenty patients (12 males and 8 females; mean age, $55.50 \pm 14.57$ years, range, 16-85 years) with anterior or middle mediastinal metastasis underwent CT-guided trans-sternal ${ }^{125}$ I seed implantation (Figure 1). Inclusion criteria were all patients with malignant tumor diagnosed by histology, with metastases confirmed by further histology or radiographic options (enhanced CT or MRI, PET-CT); well-controlled primary tumor; patients who failed or refused to undergo chemotherapy, external radiotherapy, or surgery; lesions of $<7 \mathrm{~cm}$ in dimension; expected survival time of $>3$ months; Karnofsky performance scale (KPS) scores of $\geq 70$. Characteristics of the patients are listed in Table 1.

\section{Instruments and equipment}

CT (CT590, GE, USA), ${ }^{125}$ I seed (HTA, Beijing, China; Seeds Biological Pharmacy, Tianjin, China; half-life of 59.6 days; average energy of 27.4-35.5 kV; length: $4.5 \mathrm{~mm}$; diameter: $0.8 \mathrm{~mm}$; half layer; $0.025 \mathrm{~mm}$ of lead), Hakko interventional steel puncture needle $(18 \mathrm{G}, 15 \mathrm{~cm})$, and a brachytherapy treatment planning system (BTPS, Beijing Astro Technology, Beijing, China) were used in the study.

\section{Procedures for ${ }^{125}$ I implantation}

All procedures were performed by the same interventional radiologist ZG Zhou, who has 20 years of experience in CT-guided percutaneous interventions. Contrast material-enhanced CT was performed in each patient, up to 7 days before surgery.

Pre-operative treatment plan was developed within 3 days of surgery using BTPS by two radiologists (T. Liu and Y.L. Chen). Gross tumor volume (GTV), planned target volume, and surrounding vital structures were measured based on the contrast material-enhanced CT images. BTPS simulated the needle path and calculated the number of seed. The prescribed dose per volume was 110-140 Gy.

BTPS generated a dose-volume histogram (DVH) and isodose curves of different percentages. Great care was taken to ensure that all needle paths avoided vital structures, including large blood vessels (Figure 2). On the day of surgery, a patient was placed on the CT gantry, and routine CT imaging (parameters: voltage, $120 \mathrm{kV}, 200 \mathrm{~mA}$ per section; section thickness, $5 \mathrm{~mm}$; rotation time, $0.75 \mathrm{~s}$ ) was performed to locate the lesion site. After local infiltration, anesthesia with $5-20 \mathrm{ml}$ of $1 \%$ lidocaine (Hunan Kelun, Yueyang, China) was performed, and 18-gauge needles were used to directly puncture the sternum under CT guidance, based on pre-operative plan (Figure 3). The needles were twirled gradually and positioned against the lesions' deepest margins. Intra-operative real-time plan was performed based on positions of the needles and ${ }^{125} \mathrm{I}$ seed distribution. After completion of surgery, a routine chest CT scan was taken immediately to confirm the presence or absence of complications, such as pneumothorax and hemorrhage. Dose evaluation was performed based on the recorded images (Figure 4). 
Table 1. Basic characteristics and dose parameters in pre-operative and post-operative plans of 20 patients, and their clinical responses after ${ }^{125}$ I implantation

\begin{tabular}{|c|c|c|c|}
\hline Variable & $\begin{array}{l}\text { Patients' no. } \\
\qquad(n=20)\end{array}$ & Variable & $\begin{array}{l}\text { Patients' no. } \\
\qquad(n=20)\end{array}$ \\
\hline Age (years, mean \pm SD) & $55.50 \pm 14.57$ & \multicolumn{2}{|l|}{$V_{150}$} \\
\hline \multicolumn{2}{|l|}{$\operatorname{Sex}(n, \%)$} & Post-operative $(\%$, mean \pm SD) & $66.86 \pm 7.53$ \\
\hline Male & $12(60.0)$ & Pre-operative $(\%$, mean \pm SD) & $64.33 \pm 6.95$ \\
\hline Female & $8(40.0)$ & $P$-value & 0.243 \\
\hline \multicolumn{2}{|l|}{ Primary cancer $(n, \%)$} & \multicolumn{2}{|l|}{$V_{200}$} \\
\hline Adrenal cortical carcinoma & $1(5.0)$ & Post-operative $(\%$, mean \pm SD $)$ & $42.95 \pm 9.11$ \\
\hline Breast cancer & $3(15.0)$ & Pre-operative $(\%$, mean \pm SD) & $35.52 \pm 8.93$ \\
\hline Esophageal cancer & $1(5.0)$ & $P$-value & 0.014 \\
\hline Lung adenocarcinoma & $2(10.0)$ & \multicolumn{2}{|l|}{$\mathrm{Cl}$} \\
\hline Lung squamous cell carcinoma & $6(30.0)$ & Post-operative & $0.65 \pm 0.06$ \\
\hline \multirow{2}{*}{$\begin{array}{l}\text { Mediastinal keratinized squamous cell } \\
\text { carcinoma }\end{array}$} & \multirow[t]{2}{*}{$1(5.0)$} & Pre-operative & $0.67 \pm 0.08$ \\
\hline & & $P$-value & 0.411 \\
\hline Primary mediastinal squamous cell carcinoma & $2(10.0)$ & \multicolumn{2}{|l|}{$\mathrm{El}$} \\
\hline Small cell lung carcinoma & $1(5.0)$ & Post-operative $(\%$, mean \pm SD) & $40.79 \pm 13.72$ \\
\hline Thymoma B2 & $2(10.0)$ & Pre-operative $(\%$, mean \pm SD) & $40.62 \pm 15.22$ \\
\hline Thymoma C & $1(5.0)$ & $P$-value & 0.881 \\
\hline \multicolumn{2}{|l|}{ Masses location $(n, \%)$} & \multicolumn{2}{|l|}{$\mathrm{HI}$} \\
\hline Anterior mediastinum & $14(70.0)$ & Post-operative $(\%$, mean \pm SD) & $27.90 \pm 7.53$ \\
\hline Middle mediastinum & $4(20.0)$ & Pre-operative $(\%$, mean \pm SD) & $31.78 \pm 7.28$ \\
\hline Anterior and middle mediastinum & $2(10.0)$ & $P$-value & 0.126 \\
\hline \multicolumn{2}{|l|}{$\operatorname{KPS}(n, \%)$} & \multicolumn{2}{|l|}{ Mean number of implanted seeds } \\
\hline 70 & $7(35.0)$ & Post-operative (mean \pm SD) & $31.05 \pm 18.94$ \\
\hline 80 & $10(50.0)$ & Pre-operative (mean \pm SD) & $30.85 \pm 20.70$ \\
\hline 90 & $3(15.0)$ & $P$-value & 0.247 \\
\hline Largest dimension $(\mathrm{cm}$, mean $\pm \mathrm{SD})$ & $4.11 \pm 1.79$ & \multicolumn{2}{|l|}{ 2-month follow-up } \\
\hline \multicolumn{2}{|l|}{ GTV } & Number of patients & 20 \\
\hline Post-operative $\left(\mathrm{cm}^{3}\right.$, mean $\left.\pm \mathrm{SD}\right)$ & $26.69 \pm 25.22$ & \multirow[t]{2}{*}{ Local control efficacy } & $3 \mathrm{CR}, 10 \mathrm{PR}$ \\
\hline Pre-operative $\left(\mathrm{cm}^{3}\right.$, mean $\left.\pm \mathrm{SD}\right)$ & $26.84 \pm 26.96$ & & $7 \mathrm{SD}, 0 \mathrm{PD}$ \\
\hline$P$-value & 0.723 & Local control rate (\%) & 65.0 \\
\hline \multicolumn{2}{|l|}{ Median prescribed dose } & \multirow{2}{*}{$\begin{array}{l}\text { Sum of longest dimension decrease } \\
\text { from baseline }(\mathrm{cm} \text {, mean } \pm \mathrm{SD})\end{array}$} & $-1.63 \pm 1.33$ \\
\hline Post-operative (Gy, mean \pm SD) & $69.81 \pm 19.53$ & & \\
\hline Pre-operative $(G y$, mean $\pm S D)$ & $75.92 \pm 24.61$ & \multicolumn{2}{|l|}{ 6-month follow-up } \\
\hline$P$-value & 0.079 & Number of patients & 17 \\
\hline \multicolumn{2}{|l|}{$\mathrm{D}_{90}$} & \multirow[t]{2}{*}{ Local control efficacy } & $2 \mathrm{CR}, 9 \mathrm{PR}$ \\
\hline Post-operative (Gy, mean \pm SD) & $134.30 \pm 14.53$ & & 5 SD, 1 PD \\
\hline Pre-operative $(G y$, mean $\pm S D)$ & $139.42 \pm 14.49$ & \multirow{2}{*}{$\begin{array}{l}\text { Local control rate }(\%) \\
\text { Sum of longest dimension decrease } \\
\text { from baseline }(\mathrm{cm} \text {, mean } \pm \text { SD) }\end{array}$} & 64.7 \\
\hline$P$-value & 0.015 & & $-1.80 \pm 1.47$ \\
\hline \multicolumn{2}{|l|}{$V_{90}$} & \multicolumn{2}{|l|}{ 12-month follow-up } \\
\hline Post-operative (\%, mean \pm SD) & $96.10 \pm 1.55$ & \multirow{3}{*}{$\begin{array}{l}\text { Number of patients } \\
\text { Local control efficacy }\end{array}$} & 13 \\
\hline Pre-operative $(\%$, mean $\pm S D)$ & $97.15 \pm 2.09$ & & $1 \mathrm{CR}, 6 \mathrm{PR}$ \\
\hline$P$-value & 0.013 & & $4 \mathrm{SD}, 2 \mathrm{PD}$ \\
\hline \multicolumn{2}{|l|}{$V_{100}$} & Local control rate (\%) & 53.8 \\
\hline Post-operative $(\%$, mean \pm SD) & $92.69 \pm 1.93$ & Sum of longest dimension decrease & $-1.62 \pm 1.98$ \\
\hline Pre-operative $(\%$, mean \pm SD) & $94.28 \pm 2.15$ & from baseline $(\mathrm{cm}$, mean $\pm \mathrm{SD})$ & \\
\hline
\end{tabular}

Cl - conformity index; CR - complete response; El - external index; GTV - gross tumor volume; HI - homogeneity index; KPS - Karnofsky performance scale; $P D$ - progressive disease; $P R$ - partial response; $S D$ - stable disease 

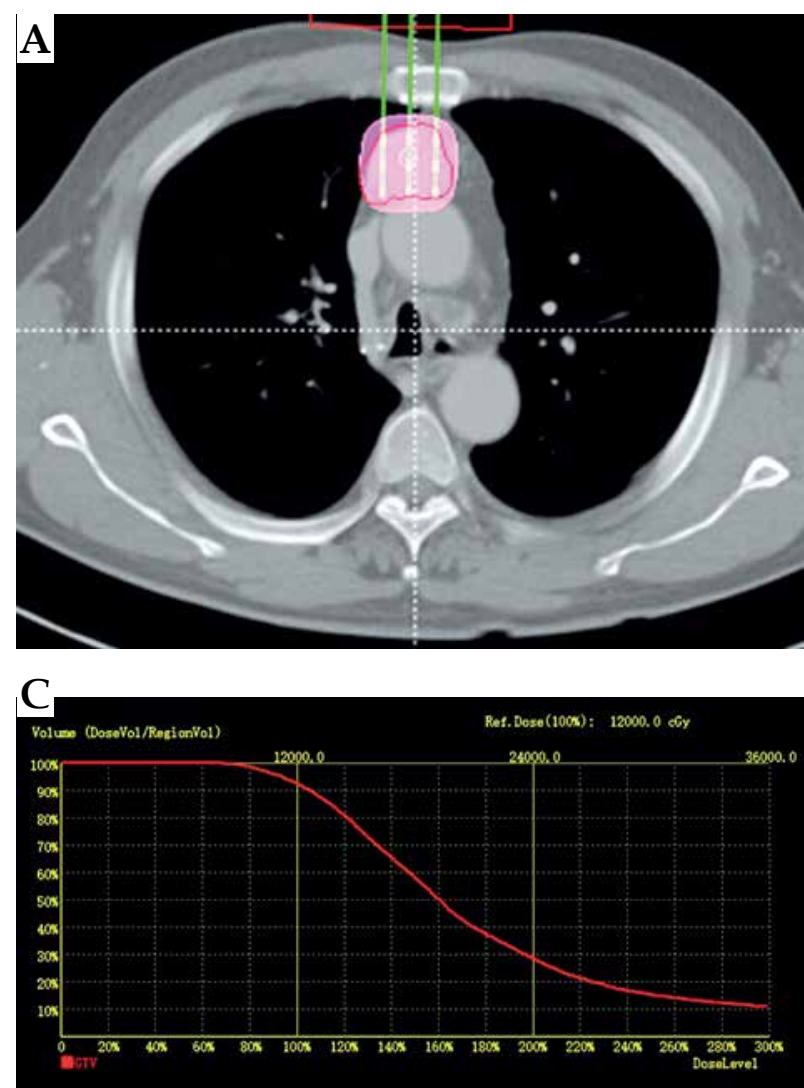

\section{Follow-up and evaluation criteria}

Any complications were noted based on the CT images taken immediately after surgery. Dose parameters of the pre-operative and post-operative plans, including $\mathrm{D}_{90}, \mathrm{~V}_{90}, \mathrm{~V}_{100}, \mathrm{~V}_{150}, \mathrm{~V}_{200}$, mean conformity index (CI), external index (EI), and homogeneity index (HI) were carefully recorded. $\mathrm{D}_{90}$ was defined as the dose received by $90 \%$ of target volume, and $V_{100}$ was defined as the percentage of target volume receiving $100 \%$ of the prescribed dose. $A D_{90}$ of at least $90 \%$ of the prescribed dose and $a V_{100}$ that corresponded to at least $90 \%$ of the target volume is the recommended standard of care. $\mathrm{V}_{150}$ and $\mathrm{V}_{200}$ corresponded to the target volumes receiving $150 \%$ and $200 \%$ of the prescribed dose [13]. When the actual dose delivered and identified met the pre-operative planed standard of care, it was considered to be a satisfactory outcome. Contrast material-enhanced CT images were obtained at 2- to 3-month intervals within 1 year of surgery, and then at 3-month to 6-month intervals. The sum of the longest dimensions was recorded as the size of target lesion. Local therapeutic efficacy was evaluated according to the size of tumor. Complete response (CR) was defined as disappearance of the target lesion, or only accumulative ${ }^{125}$ I seed shadows were detectable by image analysis (Figure 5). Partial response (PR) was evaluated as more than a $30 \%$ decrease in the dimension of target lesion, taking baseline as a reference (Figure 6). Stable disease (SD) was defined as neither PR nor progressive disease (PD), and PD as more than a $20 \%$ increase in the dimension of target lesion, taking as refer-

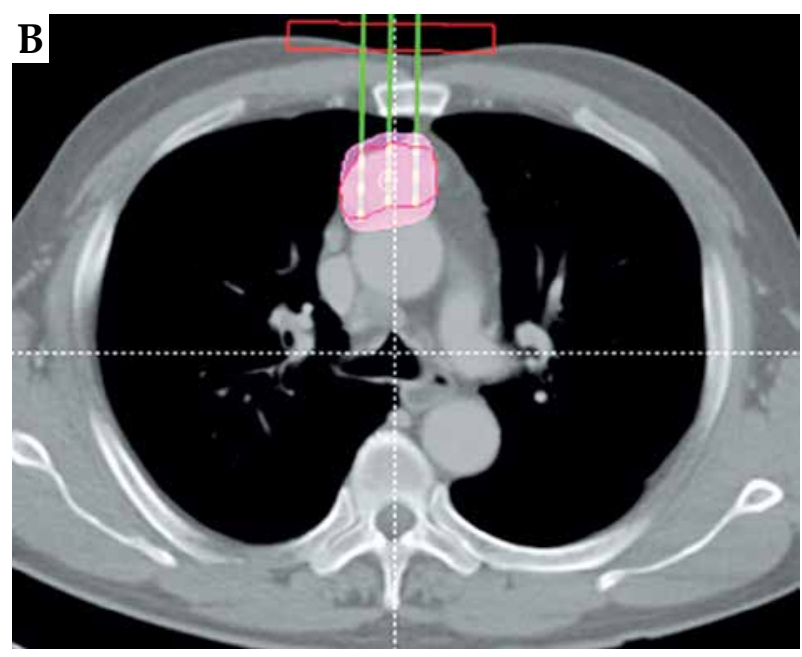

Fig. 2. Case 1: A 61-year-old male with lung squamous cell carcinoma. Pre-operative plan (A, B). BTPS simulated needle path, and seed number and distribution were calculated; the DVH (C). Prescribed dose was 120 Gy, $\mathrm{D}_{90}$ was $136.88 \mathrm{~Gy}$, and $\mathrm{V}_{100}$ was $95 \%$

ence the smallest dimension from the time the treatment was initiated.

\section{Statistical analysis}

All statistical analyses were performed using SPSS version 22.0 (IBW, NY, USA). The measured data were presented as mean \pm standard deviation. Wilcoxon signed-rank test was used to analyze the data, and differences were considered statistically significant if $p$-values were $<0.05$.

\section{Results}

Table 1 shows the differences in dose parameters between post-operative and pre-operative plans. A total of 22 lesions were treated with ${ }^{125}$ I implantation in twenty patients. All the procedures were successfully completed. The mean number of implanted ${ }^{125}$ I seeds was 31.05 \pm 18.94 (range, 6-84 seeds). The mean $\mathrm{D}_{90}, \mathrm{~V}_{90}, \mathrm{~V}_{100}, \mathrm{~V}_{150}$, $\mathrm{V}_{200}, \mathrm{CI}$, EI, and HI were $134.30 \pm 14.53 \mathrm{~Gy}, 96.1 \pm 1.55 \%$, $92.69 \pm 1.93 \%$, $66.86 \pm 7.53 \%, 42.95 \pm 9.11 \%, 0.65 \pm 0.06 \%$, $40.79 \pm 13.72 \%$, and $27.90 \pm 7.53 \%$, respectively. Statistically significant differences were found for $\mathrm{D}_{90}, \mathrm{~V}_{90}, \mathrm{~V}_{100}$, and $V_{200}$, with $p=0.015,0.013,0.009$, and 0.014 , respectively (Table 1 ). The ${ }^{125}$ I seed distribution of two patients did not meet the requirements. $\mathrm{D}_{90}$ values of those patients were 109.69 Gy and 109.21 Gy, which were lower than the prescribed dose. The $\mathrm{V}_{100}$ values of the 2 patients were $89.8 \%$ and $89.7 \%$, respectively, which were $<90 \%$. The satisfaction rate of ${ }^{125} \mathrm{I}$ seeds distribution was $90 \%$. 

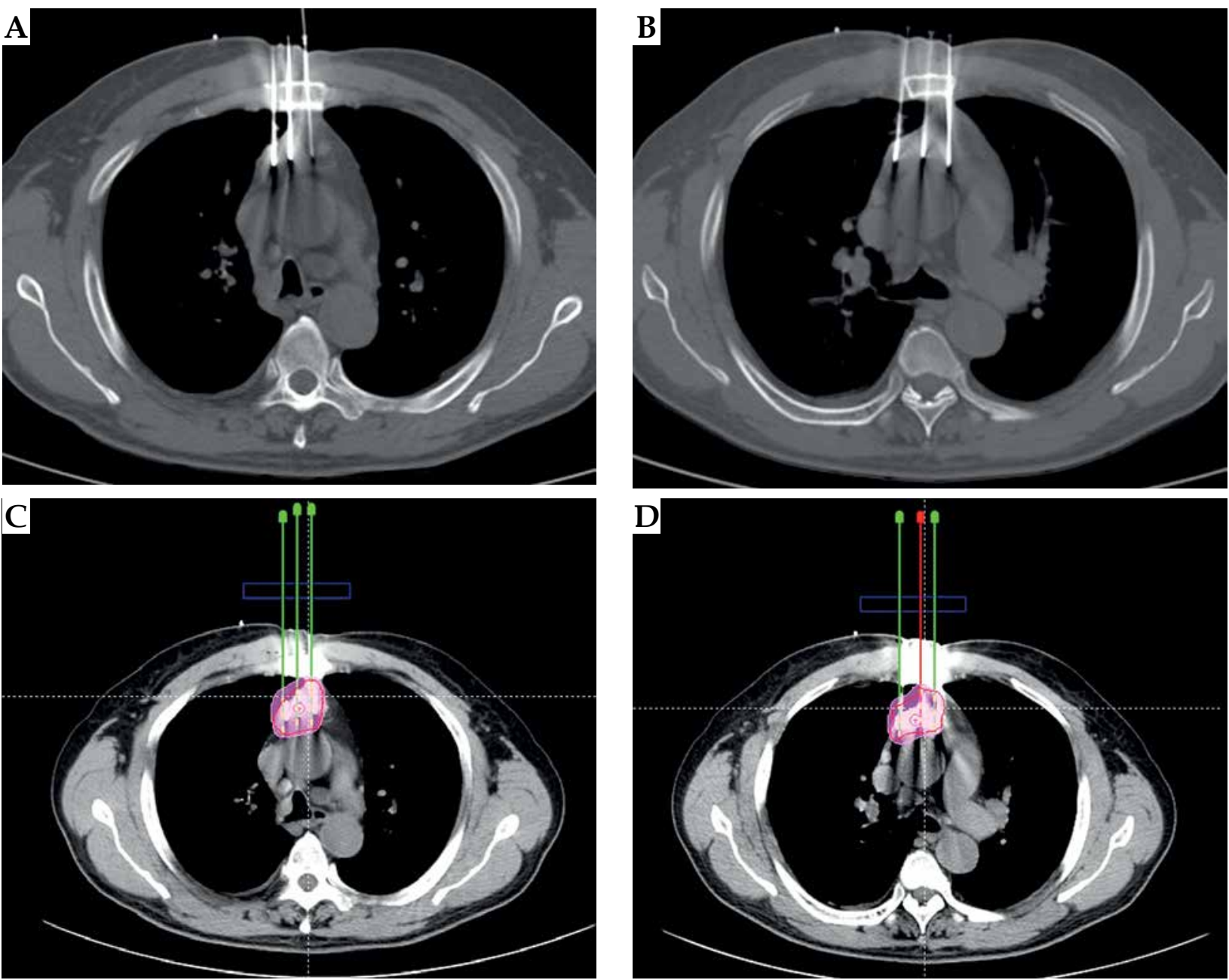

Fig. 3. Case 1: The needles punctured via the trans-sternal route (A, B); Intraoperative real-time plan (C, D)

From the time of ${ }^{125} \mathrm{I}$ implantation, the mean follow-up duration was $12 \pm 4.75$ months (range, $4-24$ months). The local control rates at 2 months, 6 months, and 1 year after surgery were $65.0 \%, 64.7 \%$, and $53.8 \%$, respectively. Table 1 demonstrates local efficacy at 2 months after ${ }^{125} \mathrm{I}$ seeds implantation. Three patients locally relapsed, and 4 patients died, but no radiation-related complications occurred throughout the follow-up period. Clinical responses of patients to ${ }^{125} \mathrm{I}$ implantation are summarized in Table 1.

Regarding toxicity, one patient had a small amount of pneumothorax, and another one had hemoptysis after surgery. No fatal complications occurred within 24 hours after intervention, and no serious complications were observed during follow-up. There was no radiation pneumonia, radiation esophagitis, or radiation skin reaction during the follow-up period.

\section{Discussion}

In recent years, CT-guided ${ }^{125}$ I seeds implantation has been used to treat various malignant solid tumors, including primary metastatic lung cancer, pancreatic, primary or metastatic liver cancer, prostate cancer, and soft-tissue sarcoma as well as salvage therapy for cervical lymph node recurrence after external beam radiation of esophageal squamous cell carcinoma. This approach offers many advantages, such as a high local control rate and good therapeutic effect with minimal injury to normal tissue, with precise anatomical location and shorter hospital stay compared to routine radiotherapy [14-23]. But there are limits for a successful treatment of mediastinal masses because of the complex anatomical structure involved: 1. The approach of masses in the anterior or middle mediastinum can be challenging because they are often adjacent to the great blood vessels; 2 . The puncture needle path is blocked by the sternum; 3 . Transpulmonary is the traditional approach, but pneumothorax and hemorrhage are common complications of CT-guided ${ }^{125} \mathrm{I}$ seeds implantation; 4 . It can be difficult to meet the required dose parameters of pre-operative plan. Thus, the application of ${ }^{125}$ I seeds for the treatment of patients with masses in the mediastinum is limited. In order to decrease the incidence of complications and increase the satisfaction rate for ${ }^{125} \mathrm{I}$ seed distribution, Lin et al. used non-transpulmonary puncture interstitial implantation of ${ }^{125}$ I seeds to treat recurrent mediastinal lymph node metastasis via parasternal, paraspinal, suprasternal, and trans-sternal 

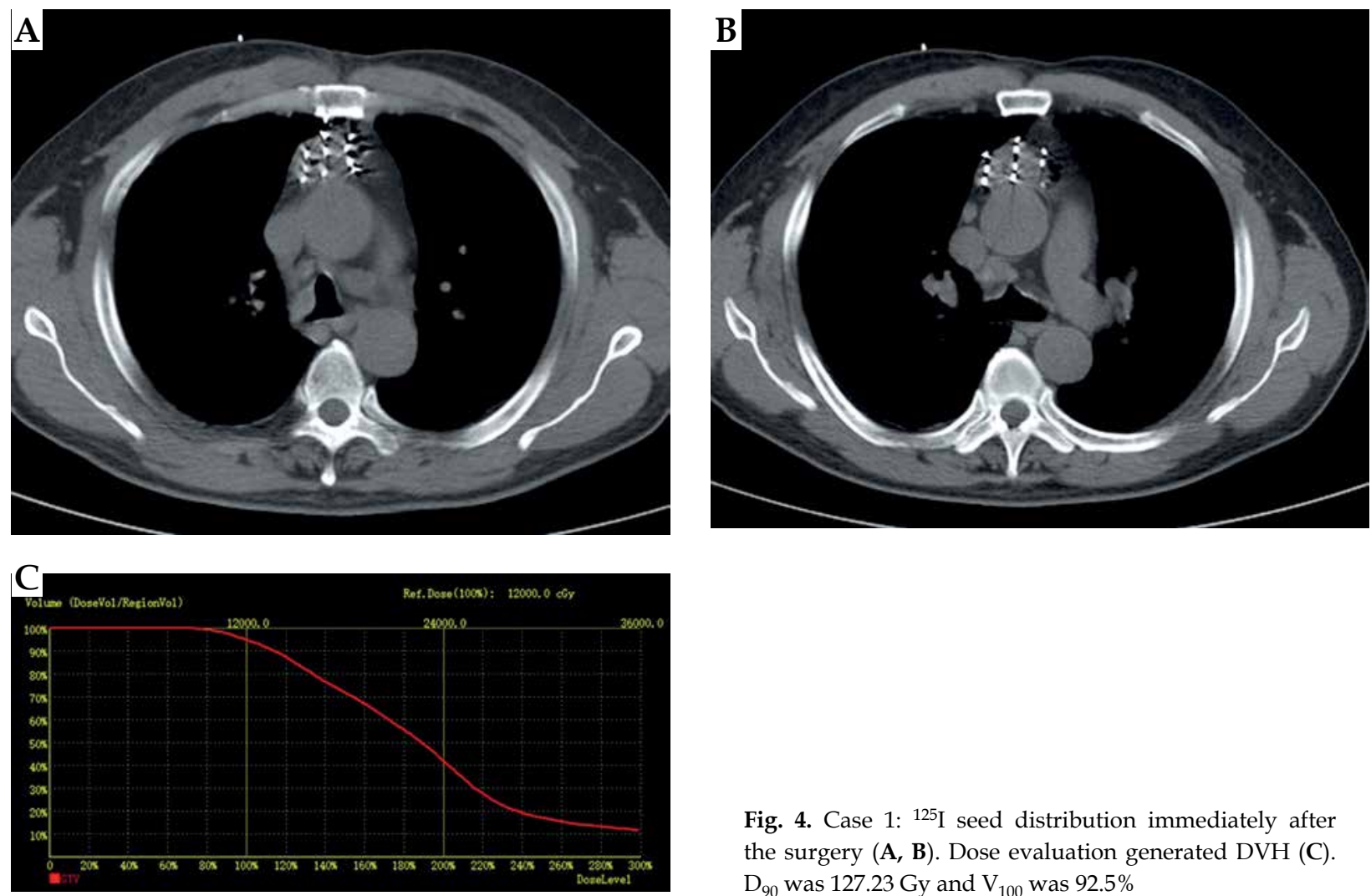

Fig. 4. Case 1: ${ }^{125} \mathrm{I}$ seed distribution immediately after the surgery (A, B). Dose evaluation generated DVH (C). $\mathrm{D}_{90}$ was $127.23 \mathrm{~Gy}$ and $\mathrm{V}_{100}$ was $92.5 \%$
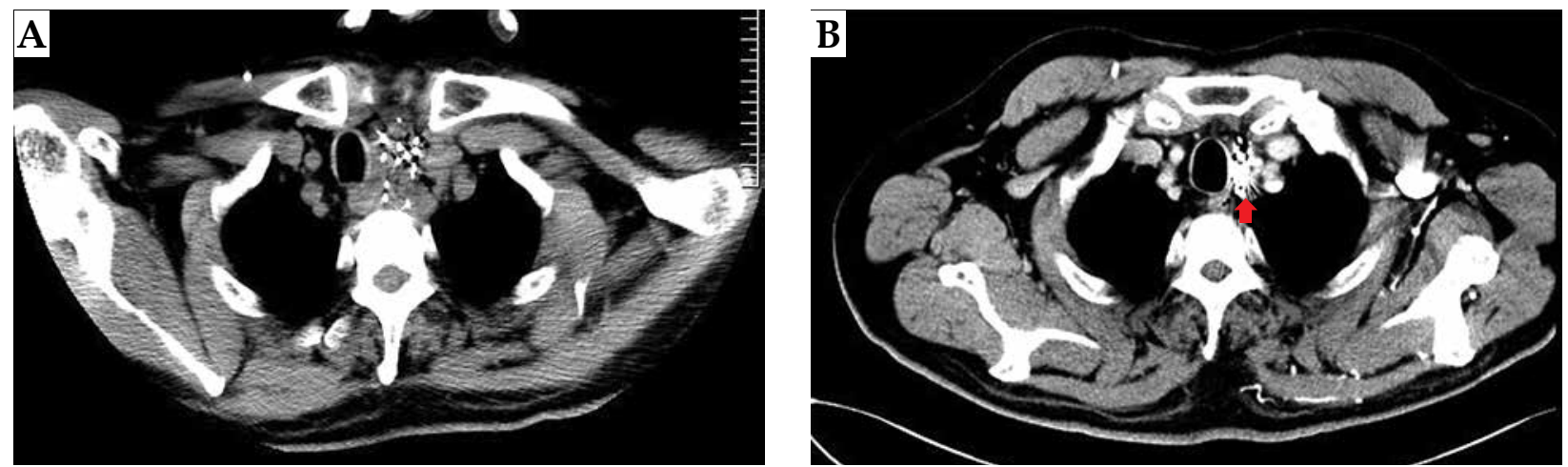

Fig. 5. Case 2: A 53-year-old patient with mediastinal metastatic lymph node recurrence from esophageal squamous cell carcinoma. ${ }^{125}$ I seeds distribution immediately after the surgery (A); Disappearance of the target lesion and only accumulative ${ }^{125} \mathrm{I}$ seed shadows were detectable by image analysis (arrow) (B); The local therapeutic efficacy was complete response

approaches [24]. Only one patient experienced a small amount of pleural cavity bleeding. For some patients with metastases in the middle or upper posterior, trans-superior vena cava and trans-tracheal approaches were also reported to be safe by Liu and Lei [25-27]. It is well-known that via the sternum is considered to be a safe approach for CT-guided percutaneous needle biopsy of mediastinal nodules $[2,11]$. In our study, we used the sternum approach for CT-guided ${ }^{125} \mathrm{I}$ seeds implantation to treat twenty patients with masses in the anterior or middle mediastinum. Only 1 patient experienced hemoptysis and 1 experienced pneumothorax, both of them cured by a conservative treatment. No serious complications were noted. A CT-guided via the sternum approach for ${ }^{125} \mathrm{I}$ seeds implantation for the treatment of lesions in the anterior or middle mediastinum has many advantages: 1 . The distance of the puncture path is short; 2 . There is a noticeable decrease in the incidence of lung injury; 3 . Most of the needles can be arranged parallelly to each other.

The efficacy and safety of ${ }^{125} \mathrm{I}$ implantation depends on the precision of puncture and dose distribution in the target area $[28,29]$. Therefore, reasonable quality control of dosimetry is an important step during ${ }^{125}$ I seeds implantation [30]. A pre-operative plan and dosimetry verification should be performed in TPS before and immediately after the implantation. In recent years, intra-operative real-time 

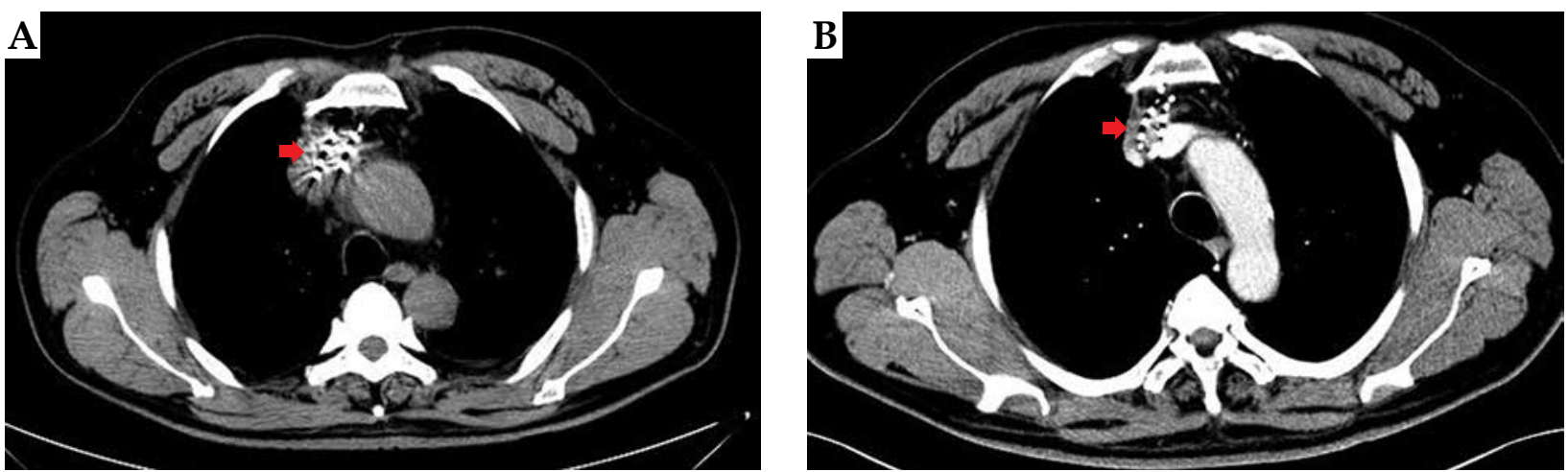

Fig. 6. Case 3: A 60-year-old patient with primary mediastinal squamous cell carcinoma. ${ }^{125}$ I seeds distribution immediately after the surgery (arrow) (A); The size of the tumor was decreased 2 months after the surgery (B) (arrow). The local therapeutic efficacy was partial response

planning was successfully implemented in many centers, and has been used to treat prostatic cancer, lung cancer, retro-peritoneal metastatic cancer, and gliomas [31-34]. It can improve the accuracy of ${ }^{125}$ I seed placement and consistency of dose distribution between post-operative and pre-operative stages. Hence, in the present study, we used intra-operative real-time planning. Immediately after surgery, the post-operative plan was performed for dose evaluation. Prescribed doses of 110-140 Gy were chosen according to previously published dose ranges [13]. Two patients in our study did not receive the required dose. $\mathrm{D}_{90}$ of the 2 patients was $109.69 \mathrm{~Gy}$ and $109.21 \mathrm{~Gy}$, while a pre-plan was to receive $110 \mathrm{~Gy}$ for both of them. $\mathrm{V}_{100}$ of the 2 patients was $89.8 \%$ and $89.7 \%$, respectively, which was somewhat less than the threshold of $90 \%$ for standard of care. Dose parameters post-operatively met the requirements of the pre-plan. Despite this finding, there were statistically significant differences in $\mathrm{D}_{90}, \mathrm{~V}_{90}, \mathrm{~V}_{100}$, and $\mathrm{V}_{200}$, with $p$-values $=0.015,0.013,0.009$, and 0.014 , respectively, between the post-operative and pre-operative plans. Some important factors to consider when formulating an intra-operative plan: 1 . The positions of needles in the plan should be the same as in the real world; $2 .{ }^{125}$ seeds should be implanted according to intra-operative real-time plan; 3 . If the dose did not meet pre-operative plan, ${ }^{125}$ I seeds should be replanted immediately.

Several studies have confirmed that CT-guided ${ }^{125} \mathrm{I}$ seed implantation for mediastinal tumors had a superior local control rate [35-37]. Gao et al. reported that CT-guided ${ }^{125} \mathrm{I}$ implantation was an effective and safe treatment for mediastinal metastatic lymph node recurrence in esophageal carcinoma. Local control rates of 3, 6, 10, and 15 months after surgery were $75.0 \%, 50.0 \%, 42.9 \%$, and $33.3 \%$, respectively [36], which are comparable to our findings. In another study, $\mathrm{Xu}$ et al. reported endobronchial ultrasound-guided iodine- 125 radioactive seed implantation for a treatment of mediastinal tumors. They found that overall response rates (complete remission + partial remission) post-operatively at 2, 4 and 6 months were $65 \%(13 / 20), 80(16 / 20)$, and $85 \%(17 / 20)$, respectively [38]. Another study reported a local control rate of $40.6 \%$, 1 year after (CT) guided ${ }^{125}$ I seed implantation for recurrent head and neck cancer after external beam radia- tion therapy [39], which is also close to the value of $53.8 \%$ found in the present study.

This study had a number of limitations. It included only twenty patients, who were followed-up for less than 2 years. Future studies should involve a larger cohort of patients and longer follow-up time. CT-guided ${ }^{125} \mathrm{I}$ seed implantation is a local treatment modality, which should be used in conjunction with effective systemic treatment.

\section{Conclusions}

CT-guided trans-sternal ${ }^{125} \mathrm{I}$ seed implantation provides a novel approach for treating various cases of mediastinal metastatic tumors.

\section{Disclosure}

The authors report no conflict of interest.

\section{References}

1. Chargari C, Deutsch E, Blanchard P et al. Brachytherapy: An overview for clinicians. CA Cancer J Clin 2019; 69: 386-401.

2. Senan S, Lagerwaard FJ, de Pan C et al. A CT-assisted method of dosimetry in brachytherapy of lung cancer. Rotterdam Oncological Thoracic Study Group. Radiother Oncol 2000; 55: 75-80.

3. Mona Sanghani, Mignano J. Intensity modulated radiation therapy: A review of current practice and future outlooks. Technol Cancer Res Treat 2018; 5: 447-450.

4. Tsubokura T, Yamazaki H, Masui K et al. Comparison of image-guided intensity-modulated radiotherapy and low-dose rate brachytherapy with or without external beam radiotherapy in patients with localized prostate cancer. Sci Rep 2018; 8: 10538 .

5. Sharma DN, Gandhi AK, Sharma S et al. Interstitial brachytherapy vs. intensity-modulated radiation therapy for patients with cervical carcinoma not suitable for intracavitary radiation therapy. Brachytherapy 2013; 12: 311-316.

6. Shirotake S, Makino S, Suzuki K et al. Clinical outcome of high dose rate brachytherapy with external beam radiotherapy for high-risk prostate cancer: a single institutional retrospective study. Jpn J Clin Oncol 2018; 49: 87-91.

7. Kee DLC, Gal J, Falk AT et al. Brachytherapy versus external beam radiotherapy boost for prostate cancer: Systematic review with meta-analysis of randomized trials. Cancer Treat Rev 2018; 70: 265-271. 
8. Jiang W, Chen $Y$, Ji Z et al. The accuracy and dosimetric analysis of 3D-printing non-coplanar template-assisted iodine-125 seed implantation for recurrent chest wall cancer. J Contemp Brachytherapy 2021; 13: 273-279.

9. Zhao Z, Yao W, Zhang T et al. Computed tomography-guided implantation of (125)I radioactive seeds in patients with malignant airway compression induced by advanced lung cancer: effectiveness and safety in 40 patients. J Contemp Brachytherapy 2020; 12: 343-350.

10. Chen J, Chen J, Lin XH et al. Application of the transosseous approach for computed tomography-guided radioactive 125-iodine seed implantation for the treatment of thoracic and abdominal lymph node metastases. J Cancer Res Ther 2019; 15: 1611-1616.

11. Wang M, Zhou ZG, Pan YW et al. Application of novel coaxial technique in performing puncture biopsy of anterior-middle mediastinal masses. J Interv Radiol 2016; 25: 329-331.

12. Chehab M, Zintsmaster S, Jafri SZ et al. CT-guided transosseous soft tissue biopsy: techniques, outcomes and complications in 50 cases. Cardiovasc Intervent Radiol 2017; 40: 14611468.

13. Bittner NH, Orio PF, 3rd, Merrick GS et al. The American College of Radiology and the American Brachytherapy Society practice parameter for transperineal permanent brachytherapy of prostate cancer. Brachytherapy 2017; 16: 59-67.

14. Wu L, Zhang Y, Zhang Z et al. Endovascular implantation of iodine-125 seed strand combined and stent placement for locally advanced pancreatic ductal adenocarcinoma with vascular invasion: a prospective single-arm pilot study. J Contemp Brachytherapy 2020; 12: 427-434.

15. Zhang Y, Liu Z, Liang Y et al. The effectiveness and prognostic factors of radioactive iodine- 125 seed implantation for the treatment of cervical lymph node recurrence of esophageal squamous cell carcinoma after external beam radiation therapy. J Contemp Brachytherapy 2020; 12: 579-585.

16. Mo Z, Zhang T, Zhang Y et al. Feasibility and clinical value of CT-guided (125)I brachytherapy for metastatic soft tissue sarcoma after first-line chemotherapy failure. Eur Radiol 2018; 28: 1194-1203.

17. Zhang W, Li J, Li R et al. Efficacy and safety of iodine-125 radioactive seeds brachytherapy for advanced non-small cell lung cancer - a meta-analysis. Brachytherapy 2018; 17: 439-448.

18. Wisely CE, Hadziahmetovic M, Reem RE et al. Long-term visual acuity outcomes in patients with uveal melanoma treated with 125I episcleral OSU-Nag plaque brachytherapy. Brachytherapy 2016; 15: 12-22.

19. Zou JL, Lu W, Chen L et al. Efficacy analysis of CT guide 125I seeds implantation combined wim chemotherapy in the treatment of unresectable non-sinall cell lung cancer. Chin J Nucl Med Mol Imaging 2019; 39: 96-99.

20. Wang G, Zhang F, Yang B et al. Feasibility and clinical value of CT-guided (125)I brachytherapy for bilateral lung recurrences from colorectal carcinoma. Radiology 2016; 278: 897905.

21. Wang H, Lu J, Zheng XT et al. Oligorecurrence non-small cell lung cancer after failure of first-line chemotherapy: computed tomography-guided (125)I seed implantation vs. second-line chemotherapy. Front Oncol 2020; 10: 470.

22. Hertzanu Y, Ye X. A valuable guideline of radioactive (125) I seeds interstitial implantation brachytherapy for pancreatic cancer. J Cancer Res Ther 2018; 14: 1453-1454.

23. Liu Q, Dai X, Zhou X et al. Comparison of TACE combined with and without iodine-125 seeds implantation therapy for advanced stage hepatocellular carcinoma: a systematic review and meta-analysis. J BUON 2019; 24: 642-649.

24. Lin $Z Y$, Chen J. Treatment of recurrent mediastinal lymph node metastasis using CT-guided nontranspulmonary punc- ture interstitial implantation of (125)I seeds: Evaluation of initial effect and operative techniques. Brachytherapy 2016; 15: 361-369.

25. Lei GY. Safety and efficacy of CT-guided percutaneous and transtracheal iodine-125 radioactive seeds implantation for recurrence and metastasis of esophageal carcinoma in the upper posterior mediastinum. Brachytherapy 2018; 17: S60-S61.

26. Liu B, Li Y, Wang Y et al. (125) Iodine brachytherapy via a trans-superior vena cava approach in patients with metastases in middle mediastinal lymph nodes: a novel approach. Asia Pac J Clin Oncol 2017; 13: 219-225.

27. Zhao M, Liu B, Li SY et al. Experimental computed tomography-guided vena cava puncture in pigs for percutaneous brachytherapy of middle mediastinal lymph node metastases. Chin Med J (Engl) 2015; 128: 1079-1083.

28. Pan TF, Lu J, Wang Y et al. Clinical application of 3D printing template-assisted 125I radioactive seed interstitial brachytherapy in treating malignant tumors. Brachytherapy 2018; 27: 740-744

29. Ji Z, Jiang YL, Guo FX et al. Dosimetry evaluation for CT guided 125I seeds implantation assisted by three-dimensional-printing coplanar coordinate template in chest malignant tumor. Chin J Nucl Med Mol Imaging 2018; 38: 4-8.

30. Tiberi D, Gruszczynski N, Meissner A et al. Influence of body mass index and periprostatic fat on rectal dosimetry in permanent seed prostate brachytherapy. Radiat Oncol 2014; 9: 93.

31. Prada PJ, Juan G, Fernández J et al. Conformal prostate brachytherapy guided by realtime dynamic dose calculations using permanent 125iodine implants: technical description and preliminary experience. Arch Esp Urol 2006; 59: 933-940.

32. Huo B, Hou CH, Ye JF et al. The study of intraoperative real-time planning by CT-guided in 125I seed implantation for thoracic malignancies. Chin J Radiat Oncol 2013; 22: 400-403.

33. Hu HY, Wang H, Peng LJ et al. The role of real-time optimization of radioactive seed implantation in treatment of gliomas. J Med Imaging 2017; 27: 209-212.

34. Zhang LJ, Zhang H, Tao., Wang ZY et al. The advantages of intraoperative TPS real-time planning in treating retroperitoneal metastatic carcinoma with 125 I seed brachytherapy. J Interv Radiol 2017; 11: 54-57.

35. Martínez-Monge R, Subtil JC, López-Picazo JM. Transoesophageal endoscopic-ultrasonography-guided 125I permanent brachytherapy for unresectable mediastinal lymphadenopathy. Lancet Oncol 2006; 7: 781-783.

36. Gao F, Li C, Gu Y et al. CT-guided 125I brachytherapy for mediastinal metastatic lymph nodes recurrence from esophageal carcinoma: effectiveness and safety in 16 patients. Eur J Radiol 2013; 82: e70-75

37. Lv J, Yang J, Zheng G et al. Clinical efficacy of 125 I radioactive seed implantation in postoperative lung metastases of malignant fibrous histiocytoma. Chin J Clin Oncol 2017; 37: 533-538.

38. Xu T, Peng WD, Gu X et al. Endobronchial ultrasound-guided iodine-125 radioactive seed implantation as a novel therapy for mediastinal tumors. Cancer Biother Radiopharm 2019; 37: 547-550

39. Ji Z, Jiang $Y$, Tian $S$ et al. The effectiveness and prognostic factors of CT-guided radioactive I-125 seed implantation for the treatment of recurrent head and neck cancer after external beam radiation therapy. Int J Radiat Oncol Biol Phys 2019; 103: 638-645. 